\title{
Investigation of Indium Trihydride Molecule and Its Clusters Using Density Functional Theory for Semiconductor Application
}

\author{
B. Karthikeyan ${ }^{a, *}$, K. Sakthiraj ${ }^{b}$ And P. SenthilkumaR ${ }^{c}$ \\ ${ }^{a}$ Department of Physics, Mepco Schlenk Engineering College, Sivakasi 626 005, India \\ ${ }^{b}$ Department of Physics, Kamaraj College of Engineering and Technology, \\ Virudhunagar 626 001, India \\ ${ }^{c}$ Department of Chemical Engineering, Sri Sivasubramaniya Nadar College of Engineering, \\ Kalavakkam 603 110, India
}

Received: 06.05.2020 \& Accepted: 15.09.2020

Doi: 10.12693/APhysPolA.139.14 *e-mail: karthi.madhubalan@gmail.com

\begin{abstract}
It is widely known that few metal hydrides are potential candidates as atom sources for organo-metallic vapor phase epitaxial growth of III-V semiconductor layers. For such an application, it is important to know the structure, bond lengths, bond angles and other molecular properties of metal hydrides such as $\mathrm{BH}_{n}, \mathrm{AlH}_{n}, \mathrm{GaH}_{n}, \mathrm{AsH}_{n}, \mathrm{InH}_{n}$ and $\mathrm{SbH}_{n}$. In this view of semiconductor application, indium trihydride clusters $\left(\mathrm{InH}_{3}\right)_{n=1-3}$ have been chosen in the present study and clusters of $\mathrm{InH}_{3}$ molecules, i.e., $\mathrm{InH}_{3}, \mathrm{In}_{2} \mathrm{H}_{6}$ and $\mathrm{In}_{3} \mathrm{H}_{9}$, have been investigated using density functional theory in conjunction with the B3LYP-LANL2dZ basis set which is the most popular effective core potential for the computations on metal containing systems. Various parameters including zero point vibrational energy, thermal energy, specific heat, entropy, heat of formation, vibrational frequencies and their intensities, etc., were derived. The infrared spectral features of indane $\left(\mathrm{InH}_{3}\right)$, diindane $\left(\mathrm{In}_{2} \mathrm{H}_{6}\right)$ and triindane $\left(\mathrm{In}_{3} \mathrm{H}_{9}\right)$ were compared with the already reported set of data. It was predicted based on the results obtained in the present study that the stability of the $\mathrm{In}_{3} \mathrm{H}_{9}$ molecule was possible, since no imaginary frequencies in the IR spectra and favourable heats of formation were obtained. The results obtained in the present study gave a new perspective of the $\left(\mathrm{InH}_{3}\right)_{n=1,2,3}$ material.
\end{abstract}

topics: indium trihydride, DFT analysis, geometry, IR spectra

\section{Introduction}

Interest in metal hydrides arises from the fact that they are sources of the corresponding elements to generate layers of group III-V semiconductors. For this reason, hydrides such as $\mathrm{BH}, \mathrm{AlH}, \mathrm{GaH}$, $\mathrm{AsH}, \mathrm{InH}, \mathrm{SbH}, \mathrm{RbH}, \mathrm{CsH}$, etc., have been studied by many authors [1-6]. For semiconductor applications, the choice of metal hydride films for the use in semiconductor devices plays a crucial role and the criterions like band gap and hydrogen desorption temperature have to be accounted for the further consideration of the material [7]. Also, the methods of deposition of films should be compatible with those used for the fabrication of optoelectronic devices [8].

Among various metal hydrides, indane $\left(\mathrm{InH}_{3}\right)$ has more significance in nature, for instance, it is the only experimentally observed molecule and hence it can be used to gauge the quality of theoretical calculations, too. Aluminium, gallium and indium trihydrides in solid argon were successfully synthesized using different synthesis techniques and a prediction of vibrational frequencies was done using density functional theory (DFT) and CCD methods [9].
The stability of the group 13 hydrides in the oxidation state + III of the metal was analyzed using the $a b$ initio Moller-Plesset (MP2) calculations [10]. An extensive study of $\mathrm{InH}$ and its complexes was performed to verify the assignments of the vibrational bands based on the $a b$ initio calculations using DFT by adopting the Perdew-Wang correlation and the exchange function [11].

A systematic investigation of the stability, structure and properties of indium trihydride complexes was performed and a detailed comparison of $\mathrm{InH}_{3}$ with other lighter group 13 metal trihydrides complexes was also done [12]. The structural, electronic and thermochemical properties of various indium compounds including $\mathrm{InH}_{3}$ were studied by $a b$ initio and statistical thermodynamic methods [13]. A laser ablation matrix isolation infrared spectroscopy experiment was carried out to understand the reactions of laser-ablated In atoms with pure hydrogen and pure deuterium. The emission and infrared spectra were also recorded for $\left(\mathrm{InH}_{3}\right)_{n}$ and $\left(\mathrm{InD}_{3}\right)_{n}$ compounds [14]. In view of the fact that the controlled decomposition of these halides has led to an array of clusters and related 
complexes, the first mixed-oxidation-state of the indium sub-halide complex anion was synthesized and the characterization of the same was done using a controlled decomposition of an indium trihydride adduct [15].

A systematic investigation of indium hydrides' structure and physical properties at high pressures was performed and the superconductive behaviors of the optimum static structures was also studied [16]. A spectroscopic study of the decomposition of a Lewis base adduct of indane was reported by the researchers [17] and it revealed fruitful information on the synthesis of the exceptionally stable indane complex $\left[\operatorname{InH}_{3}\left(\mathrm{IPr}^{*}\right)\right]$. In view of the significances reported earlier, indane, diindane and triindane have been chosen in the present study with the aim to get a better understanding of their properties.

In order to optimize the geometry and verify the assignments of the vibrational bands, DFT has been performed on indium trihydride $\left(\mathrm{InH}_{3}\right)_{n}$, where $n=1,2,3$, using a B3LYP-LANL2DZ basis set. The reason for choosing this technique is that DFT has a great advantage over the HartreeFock (HF) method in describing electron correlation effects and it has favorable scaling properties with respect to the molecular size when compared to the post-Hartree-Fock methods. As a result, DFT is a widely used computational approach for studying large transition metal containing compounds [18]. An electron core potential (ECP) basis like LANL2DZ plays an important role in the DFT analysis because of (i) reducing a computational cost on systems with many metal centers, e.g., metal or metal oxide clusters or slabs, and (ii) circumventing the necessity to describe relativistic effects in deep core electrons [19]. Such a basis set is always useful for efficient calculations on molecules containing heavy elements as the chemically irrelevant core electrons are not explicitly part of the electronic problem and are replaced by a core potential function instead. It is worth to mention here that the indane and diindane molecules have been investigated by many authors. However, to the best of our knowledge, there have not been any attempts on the study of structural geometry and molecular properties of the triindane molecule $\left(\mathrm{In}_{3} \mathrm{H}_{9}\right)$ using the LANL2DZ basis set. Therefore, all the compounds chosen in the present study have been optimized using the B3LYP-LANL2DZ set and the parameters like zero point vibrational energy, thermal energy, specific heat, entropy, heat of formation, vibrational frequencies and their intensity, etc., have been evaluated and discussed along with the already reported values for better justification.

\section{Computational procedure}

All the calculations carried out in this study were performed using the Gaussian 03 suite of programs [20]. The geometry optimizations on the molecules $\left(\mathrm{InH}_{3}\right)_{n=1-3}$ were performed using the B3LYP functional and LANL2DZ basis set. The B3LYP functional is composed of Becke's three-parameter hybrid exchange functional (B3) [21, 22], as implemented in Gaussian 03 [23], and the correlation functional of Lee, Yang and Parr (LYP) [24]. Zero point vibrational energy, thermal energy, specific heat, entropy, heat of formation, vibrational frequencies and their intensities, etc., were calculated at the same level of theory. A few additional calculations with larger basis sets were carried out as a check on the effects of the basis set truncation. No symmetry restrictions were considered in the structural optimization. The optimized parameters and IR spectral features were given in the following section with the necessary explanation.

\section{Results and discussion}

The optimized structures presented here have true energy minima as no imaginary frequency is obtained. The optimized geometries of indane, diindane and triindane are depicted using a ballstick model, as shown in Fig. 1. Their bond lengths and bond angles were optimized at the B3LYP/LANL2DZ level. Table I gives a very clear picture of the comparison between the calculated structural parameters and the already reported values.

It could be seen from Table I that the bond lengths and bond angles of the molecules are in good agreement with the theoretical or experimental values reported earlier. It is noteworthy that many of the reported values listed for the $\mathrm{InH}_{3}$ and $\mathrm{In}_{2} \mathrm{H}_{6}$ molecules in Table $\mathrm{I}$ were derived only by using ab initio calculations based on the lower basis

TABLE I

Optimized bond lengths and bond angles for the $\left(\mathrm{InH}_{3}\right)_{n}$ molecule, where $n=1,2,3$.

\begin{tabular}{|c|c|c|c|c|c|c|}
\hline \multirow{2}{*}{ Mol. } & \multirow{2}{*}{ Ref. } & \multicolumn{3}{|c|}{ Bond length $[\AA]$} & \multicolumn{2}{|c|}{ Bond angle $\left[{ }^{\circ}\right.$ ] } \\
\hline & & $\mathrm{In}-\mathrm{H}^{t}$ & $\mathrm{In}-\mathrm{H}^{b}$ & In-In & $\mathrm{In}-\mathrm{H}^{b}-\mathrm{In}$ & $\mathrm{H}^{t}-\mathrm{In}-\mathrm{H}^{t}$ \\
\hline \multirow{7}{*}{$\mathrm{InH}_{3}$} & this work & 1.735 & & & & 120.0 \\
\hline & Ref. [14] & 1.728 & & & & 120.0 \\
\hline & Ref. [13] & 1.766 & & & & 119.0 \\
\hline & Ref. [12] & 1.710 & & & & - \\
\hline & Ref. [11] & 1.757 & & & & - \\
\hline & Ref. [10] & 1.725 & & & & 120.0 \\
\hline & Ref. [9] & 1.754 & & & & 120.0 \\
\hline \multirow{6}{*}{$\mathrm{In}_{2} \mathrm{H}_{6}$} & this work & 1.717 & 1.960 & 3.030 & 108.2 & 132.2 \\
\hline & Ref. [14] & 1.712 & 1.940 & - & 100.8 & 131.1 \\
\hline & Ref. [25] & 1.739 & 1.976 & 3.020 & 99.7 & - \\
\hline & Ref. [11] & 1.739 & 1.964 & - & 98.9 & 133.0 \\
\hline & Ref. [10] & 1.710 & 1.946 & 2.961 & 80.9 & 130.2 \\
\hline & Ref. [26] & 1.720 & 1.968 & 3.009 & 99.7 & - \\
\hline \multirow{4}{*}{$\mathrm{In}_{3} \mathrm{H}_{9}$} & this work & 1.719 & 1.851 & 3.089 & 98.1 & 131.5 \\
\hline & & 1.718 & 2.079 & & 101.3 & \\
\hline & Ref. [11] & 1.739 & 1.880 & - & 97.4 & 133.5 \\
\hline & & 1.738 & 2.024 & - & 100.9 & \\
\hline
\end{tabular}


Thermochemical parameters derived for the $\left(\mathrm{InH}_{3}\right)_{n}$ molecule, where $n=1,2,3$.

TABLE II

\begin{tabular}{l|c|c|c|c|c}
\hline \hline Molecule & $\begin{array}{c}\text { Heat of formation } \\
{[\mathrm{kJ} / \mathrm{mol}]}\end{array}$ & $\begin{array}{c}\text { Zero point vibrational } \\
\text { energy }[\mathrm{kcal} / \mathrm{mol}]\end{array}$ & $\begin{array}{c}\text { Thermal energy } \\
{[\mathrm{kcal} / \mathrm{mol}]}\end{array}$ & $\begin{array}{c}\text { Specific heat } c_{v} \\
{[\mathrm{cal} /(\mathrm{mol} \mathrm{K})]}\end{array}$ & $\begin{array}{c}\text { Entropy } S \\
{[\mathrm{cal} /(\mathrm{mol} \mathrm{K})]}\end{array}$ \\
\hline $\mathrm{InH}_{3}$ & -21.4766 & 10.17691 & 12.224 & 8.930 & 58.205 \\
$\mathrm{In}_{2} \mathrm{H}_{6}$ & -78.9304 & 23.45732 & 27.158 & 20.276 & 79.308 \\
$\mathrm{In}_{3} \mathrm{H}_{9}$ & -104.8073 & 35.56827 & 41.605 & 32.935 & 102.946
\end{tabular}

(a)



(c)

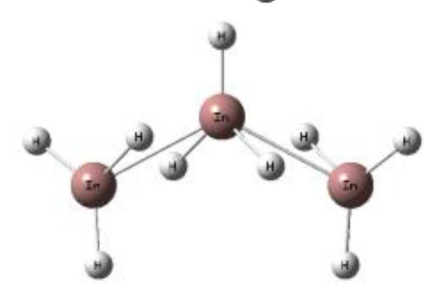

Fig. 1. Ball-stick model of the optimized geometries of (a) $\mathrm{InH}_{3}$, (b) $\mathrm{In}_{2} \mathrm{H}_{6}$ and (c) $\mathrm{In}_{3} \mathrm{H}_{9}$ at the B3LYP/LANL2DZ level.

set consisting of empirical or semi-empirical parameters in the wave equations. However, Wang and Andrews [14] followed the DFT-B3LYP/LANL2DZ set and arrived at the bond length and bond angle values as (i) $1.728 \AA$ and $120^{\circ}$ for the $\mathrm{InH}_{3}$ molecule and (ii) $1.712 \AA, 1.940 \AA, 100.8^{\circ}$ and $131.1^{\circ}$ for the $\mathrm{In}_{2} \mathrm{H}_{6}$ molecule, which are found to be coincident with the results of the present calculation. This strongly confirms the reliability of our calculations. In the case of the $\mathrm{In}_{3} \mathrm{H}_{9}$ molecule, Qiang Fu et al. [11] obtained the structural parameters using the DFT approach based on a contracted basis. It was found that the values obtained in the present study satisfactorily coincide with these values which further confirms the reliability of the LANL2dZ basis set. After performing a successful optimization of all the three molecules, thermochemical parameters, including zero point vibrational energy, thermal energy, specific heat, entropy and heat of formation, were also derived and entered in Table II.

Generally, one of the thermodynamical parameters called the heat of formation is very useful in analyzing the stability of isomeric compounds. The more negative the heat of formation, the greater is the stability. In the present study, heats of formation have been calculated by considering the direct and dimerization reaction equations [14] and they are entered in Table II. It is evident from the values of heats of formation that the stability of the compound increases with increasing the polymerization of metal hydrides. However, this interesting information can be verified only with the help of future experiments.



Fig. 2. Infrared spectra in the $2000-200 \mathrm{~cm}^{-1}$ region for (a) $\mathrm{InH}_{3}$, (b) $\mathrm{In}_{2} \mathrm{H}_{6}$ and (c) $\mathrm{In}_{3} \mathrm{H}_{9}$ molecule.

The simulated IR spectra of $\mathrm{InH}_{3}, \mathrm{In}_{2} \mathrm{H}_{6}$ and $\mathrm{In}_{3} \mathrm{H}_{9}$ were given in Fig. 2. The vibrational frequencies observed in the IR spectrum of $\left(\mathrm{InH}_{3}\right)_{n}$ are given in Tables III-V. It was found that there is a close correlation between the experimental or theoretical values reported earlier and the values obtained in the present study.

In the case of the $\mathrm{InH}_{3}$ molecule, Pullumbi et al. [9] synthesized aluminium, gallium and indium trihydrides by direct condensation of $\mathrm{H}$ or $\mathrm{D}$ atoms in a solid argon discharge. Their results showed that the infrared spectrum of $\mathrm{InH}_{3}$ exhibits three bands at $1754.5,613.2$ and $607.8 \mathrm{~cm}^{-1}$. According to Hunt and Schwerdtfeger [10], ab initio MP2 calculations suggested that (a) $\mathrm{In}_{2} \mathrm{H}_{6}$ is thermodynamically unstable in both the gas phase and the solid state and (b) $\mathrm{In}_{2} \mathrm{H}_{6}$ is a kinetically stable gas phase species. They obtained the values of the peaks 1784, 690 and $642 \mathrm{~cm}^{-1}$ by employing the Moller-Plesset theory. Qiang Fu et al. [11] obtained the most intense peaks in their IR spectra around 1746 and $603 \mathrm{~cm}^{-1}$ using the $(18 s 14 p 9 d) /[5 s 5 p 3 d]$ contracted basis set for indium and Pople's triplezeta plus polarization $\left(6-311 \mathrm{G}^{* *}\right)$ basis set for hydrogen. Wang and Andrews [14] also obtained the IR peaks which are found to coincide with the present results. One can notice that the values are matching with each other with a very small percentage of standard deviation to be around $2 \%$ only.

For the diindane molecule $\left(\mathrm{In}_{2} \mathrm{H}_{6}\right)$, Bennett and Connelly [26] reported the results based on empirical calculations using a pseudo-potential basis set which also yielded the same frequency 
TABLE III

Vibrational frequencies and their intensities for the $\mathrm{InH}_{3}$ molecule.

\begin{tabular}{c|c|l}
\hline \hline $\begin{array}{c}\text { Harmonic } \\
\text { frequency } \\
{\left[\mathrm{cm}^{-1}\right]}\end{array}$ & $\begin{array}{c}\text { Intensity } \\
{[\mathrm{km} / \mathrm{mol}]}\end{array}$ & \multicolumn{1}{|c}{ Literature* $^{*}$} \\
\hline 619.2194 & 295.5118 & $\begin{array}{l}613.2(0.44)^{a}, 603(276)^{d}, \\
630(347)^{e}, 602^{f}, 608^{f}\end{array}$ \\
643.4879 & 220.8508 & $642(321)^{b}, 656(245)^{e}$ \\
643.9299 & 220.4686 & \\
1731.3339 & 229.2083 & $1738(0)^{d}$ \\
1731.8095 & 229.0934 & \\
1749.0718 & 0.0136 & $1754.5(1.0)^{a}, 1784(344)^{b}$, \\
& & $1746(578)^{d}, 1753(346)^{e}$, \\
& & $1761^{s}, 1766^{f}$ \\
\hline
\end{tabular}

${ }^{*}$ references with the already reported harmonic

frequency values in $\mathrm{cm}^{-1}$ (intensity in a.u.);

${ }^{a}$ Ref. [9] (experimental values), ${ }^{b}$ Ref. [10],

${ }^{c}$ Ref. [25], ${ }^{d}$ Ref. [11], ${ }^{e}$ Ref. [14], ${ }^{f}$ Ref. [13]

\section{TABLE IV}

Vibrational frequencies and their intensities for the $\mathrm{In}_{2} \mathrm{H}_{6}$ molecule. The description of footnotes is the same as in Table III.

\begin{tabular}{|c|c|c|}
\hline $\begin{array}{c}\text { Harmonic } \\
\text { frequency } \\
{\left[\mathrm{cm}^{-1}\right]}\end{array}$ & $\begin{array}{l}\text { Intensity } \\
{[\mathrm{km} / \mathrm{mol}]}\end{array}$ & Literature* \\
\hline 159.1078 & - & $158(0)^{d}, 161(0)^{e}$ \\
\hline 206.2425 & 2.4075 & $188(4)^{d}, 205(7)^{e}$ \\
\hline 335.3424 & - & $334(0)^{d}, 345(0)^{e}$ \\
\hline 356.3115 & - & $369(0)^{d}, 364(0)^{e}$ \\
\hline 380.5232 & - & $387(0)^{e}$ \\
\hline 562.6552 & 222.6712 & $571(0)^{d}, 567(239)^{e}$ \\
\hline 563.6583 & 748.6516 & $\begin{array}{l}588(259)^{b}, 596(598)^{c} \\
574(784)^{e}\end{array}$ \\
\hline 620.3653 & - & $\begin{array}{l}607(834)^{b}, 637(140)^{c}, \\
615(0)^{d}, 629(0)^{e}\end{array}$ \\
\hline 662.4697 & - & $\begin{array}{l}679(173)^{c}, 639(116)^{d}, \\
669(0)^{e}\end{array}$ \\
\hline 740.1971 & 285.2797 & $753(261)^{b}, 751(307)^{e}$ \\
\hline 1022.2106 & 426.2814 & $\begin{array}{l}1089(420)^{b}, 1064(236)^{d}, \\
1062(486)^{e}\end{array}$ \\
\hline 1124.4037 & - & $\begin{array}{l}1104(310)^{c}, 1137(0)^{d}, \\
1165(0)^{e}\end{array}$ \\
\hline 1247.3481 & 1392.3624 & $\begin{array}{l}1261(1372)^{b}, 1247(0)^{c} \\
1276(0)^{d}, 1280(1372)^{e}\end{array}$ \\
\hline 1303.3908 & - & $1323(1275)^{c}, 1351(0)^{e}$ \\
\hline 1778.6550 & 104.5194 & $1779(137)^{d}$ \\
\hline 1779.2734 & - & \\
\hline 1782.4196 & - & \\
\hline 1784.0614 & 403.0622 & $\begin{array}{l}1837(522)^{b}, 1784(0)^{d}, \\
1810(558)^{e}\end{array}$ \\
\hline
\end{tabular}

TABLE V

Vibrational frequencies and their intensities for the $\mathrm{In}_{3} \mathrm{H}_{9}$ molecule. The description of footnotes is the same as in Table III.

\begin{tabular}{|c|c|c|}
\hline $\begin{array}{c}\text { Harmonic } \\
\text { frequency } \\
{\left[\mathrm{cm}^{-1}\right]}\end{array}$ & $\begin{array}{l}\text { Intensity } \\
{[\mathrm{km} / \mathrm{mol}]}\end{array}$ & Literature* \\
\hline 31.2611 & - & $29(0)^{d}$ \\
\hline 80.2133 & 12.6682 & \\
\hline 109.1884 & 0.1870 & $114(7)^{d}$ \\
\hline 157.6724 & 7.0749 & $154(1)^{d}$ \\
\hline 185.1132 & 0.7751 & $165(3)^{d}$ \\
\hline 226.5542 & 7.2018 & $209(6)^{d}$ \\
\hline 304.1638 & 0.2255 & $296(1)^{d}$ \\
\hline 332.8209 & 50.8007 & $324(60)^{d}$ \\
\hline 420.2446 & 344.3411 & $408(243)^{d}$ \\
\hline 426.5023 & 12.9999 & \\
\hline 506.9222 & 238.6720 & $485(173)^{d}$ \\
\hline 573.0188 & 982.0334 & $582(0)^{d}$ \\
\hline 597.9608 & 120.5438 & $585(27)^{d}$ \\
\hline 619.4998 & 14.3043 & \\
\hline 621.7022 & 70.2854 & $634(114)^{d}$ \\
\hline 696.6672 & 379.1062 & \\
\hline 727.5385 & 378.3586 & \\
\hline 783.3569 & 1165.4085 & $797(949)^{d}$ \\
\hline 855.9317 & - & $861(4)^{d}$ \\
\hline 990.6459 & 0.1066 & \\
\hline 1094.3080 & 188.1944 & $1051(4)^{d} 1137(241)^{d}$ \\
\hline 1365.1508 & 1207.7439 & $1382(166)^{d}$ \\
\hline 1386.4148 & 26.0258 & $1389(210)^{d}$ \\
\hline 1420.5936 & 301.4810 & \\
\hline 1453.2020 & 424.5342 & \\
\hline 1775.1287 & 179.5484 & \\
\hline 1775.6265 & 62.4323 & \\
\hline 1777.7737 & 11.7430 & $1777(99)^{d}$ \\
\hline 1779.5770 & 221.6918 & $1779(26)^{d}$ \\
\hline 1805.6107 & 128.8206 & $1808(210)^{d}$ \\
\hline
\end{tabular}

of about $1247 \mathrm{~cm}^{-1}$ for the latter vibration. Qiang Fu et al. [11] obtained the optimized structure of the $\mathrm{In}_{2} \mathrm{H}_{6}$ molecule for which the two terminal hydride stretches were present at 1779 and $1784 \mathrm{~cm}^{-1}$, whereas a single asymmetric bridging mode was obtained at $1247 \mathrm{~cm}^{-1}$. Hunt and Schwerdtfeger [10] made a detailed investigation of the $\mathrm{In}_{2} \mathrm{H}_{6}$ molecule, according to which the decomposition of $\mathrm{In}_{2} \mathrm{H}_{6}$ was clearly driven by the large atomization energies of the group 13 metals. Hence, the solid form of $\mathrm{In}_{2} \mathrm{H}_{6}$ was predicted to be thermodynamically unstable. Wang and Andrews [14] highlighted that $\mathrm{InH}_{n} \mathrm{IR}$ absorptions, where $n=1,2,3$, were blue shifted by $1.6,0.3$ and $10.0 \mathrm{~cm}^{-1}$, respectively. In their investigation, $\operatorname{In}_{3} \mathrm{H}_{9}$ was not chosen and it was believed that the said molecule was thermodynamically unstable. 
In the present study in Table IV, the IR spectrum of $\mathrm{In}_{2} \mathrm{H}_{6}$ reveals that the peaks present sharply at 1731, 643 and $619 \mathrm{~cm}^{-1}$ are in excellent agreement with the already reported experimental results mentioned above.

As shown in Table $\mathrm{V}$, triindane yields multiple vibrational bands for the bridging hydride at 1094, 1365,1421 and $1453 \mathrm{~cm}^{-1}$. The calculated values in the present study agree with the already reported values [11] which further confirms the reliability of the LANL2dZ basis set. It is worth to mention here that this is the first time to report the IR spectral features of the $\mathrm{In}_{3} \mathrm{H}_{9}$ molecule using the B3LYP/LANL2DZ basis set.

The optimization of triindane $\left(\mathrm{In}_{3} \mathrm{H}_{9}\right)$ yielded a local minimum with no imaginary frequencies, see Table V. This indicates that the $\mathrm{In}_{3} \mathrm{H}_{9}$ molecule can exist in a gas phase or it is thermodynamically stable. To the best of our knowledge, there are no experimentally observed IR spectra for triindane. Actually, we were trying to investigate the $\mathrm{In}_{4} \mathrm{H}_{12}$ molecule using the LANL2DZ basis set and we have obtained the imaginary frequencies which shows us that the $\mathrm{In}_{4} \mathrm{H}_{12}$ molecule cannot be thermodynamically stable in nature.

As already mentioned in the Introduction, there is a big demand in the field of semiconductor electronics for the knowledge of such hydrides whose stability is not known yet. It is known that the fabrication of advanced semiconductor devices, processes such as metal organic chemical vapor deposition and $p$ or $n$ doping by ion implantation ideally require the use of group III and group V hydrides. However, the hydrides of the heavier elements of group III and group V are unstable or in some cases are simply not known $[27,28]$. Hence, it is believed that the present study is a first step towards the experimental work on the synthesis and characterization of the $\mathrm{In}_{3} \mathrm{H}_{9}$ molecule both in the gas and solid phase so that fruitful application can be developed by technologists in future.

\section{Conclusion}

The optimized structure, thermochemical and infrared spectral properties of the $\left(\mathrm{InH}_{3}\right)_{n}$ molecule ( $n=1,2,3)$ clusters were systematically studied by using DFT with the B3LYP/LANL2DZ set. Our computational study revealed that there is an increasing possibility for the appearance of imaginary vibrational frequencies, as $n$ increases beyond the value of 3 . The bond lengths and bond angles obtained for the optimized structures of $\mathrm{InH}_{3}$, $\mathrm{In}_{2} \mathrm{H}_{6}$ and $\mathrm{In}_{3} \mathrm{H}_{9}$ were found to be coinciding with the already reported values. The ball-stick models clearly portrayed the geometries of the indane complexes chosen in the present study. It was concluded from the IR spectral data of the present investigation that there is a high chance for the observation of a more stable form of $\mathrm{In}_{3} \mathrm{H}_{9}$ molecular clusters which can be confirmed only by having the experimental knowledge on the same. It is noteworthy that the present calculations of isolated molecules do not reflect the reality of surface deposition of hydrides (due to lack of pressure, formation of In-P bonds, etc.). The present study, however, may be useful for the experimentalists to clarify the stability of these molecules.

\section{Acknowledgments}

The authors would like to thank the principals and management members of the respective colleges for their constant encouragement and support towards research.

\section{References}

[1] A.J. Downs, C.R. Pulham, Chem. Soc. Rev. 23, 175 (1994).

[2] A. Baldi, B. Dam, J. Mater. Chem. 21, 4021 (2011).

[3] R. Jaradat, M. Abu-Jafar, I. Abdelraziq, A. Mousa, T. Ouahrani, R. Khenata, AIP Adv. 8, 045017 (2018).

[4] J.E.R. Andrew, L. Weston, C.G. Van de Walle, Chem. Mater. 30, 5878 (2018).

[5] A. Schneemann, J.L. White, ShinYoung Kang et al. Chem. Rev. 118, 10775 (2018).

[6] R. Shimizu, H. Oguchi, T. Hitosugi, J. Phys. Soc. Jpn. 89, 051012 (2020).

[7] S.Zh. Karazhanov, U. Sheripov, A.G. Ulyashin, Philos. Mag. 89, 1111 (2009).

[8] S.Zh. Karazhanov, A.G. Ulyashin, Philos. Mag. 90, 2925 (2010).

[9] P. Pullumbi, Y. Bouteiller, L. Manceron, C. Mijoule, Chem. Phys. 185, 25 (1994).

[10] P. Hunt, P. Schwerdtfeger, Inorg. Chem. 35, 2085 (1996).

[11] Qiang $\mathrm{Fu}$, Lian Li, Connie H. Li, R.F. Hicks, "Synthesis of Bridging Indium Hydride on a Semiconductor Surface" (1999).

[12] C. Jones, Chem. Commun. 22, 2293 (2001).

[13] B.H. Cardelino, C.E. Moore, C.A. Cardelino, D.O. Frazier, K.J. Bachmann, J. Phys. Chem. A 105, 849 (2001).

[14] X. Wang, L. Andrews, J. Phys. Chem. A 108, 4440 (2004).

[15] M.L. Cole, C. Jones, M. Kloth, Inorg. Chem. Commun. 44, 4909 (2005).

[16] Y. Liu, D. Duan, F. Tian, H. Liu, C. Wang, X. Huang, D. Li, Y. Ma, B. Liu, T. Cui, Inorg. Chem. 54, 9924 (2015).

[17] A.R. Leverett, M.L. Cole, A.I. McKay, Dalton Trans. 48, 1591 (2019).

[18] Y. Yang, M.N. Weaver, K.M. Merz Jr., J. Phys. Chem. A 113, 9843 (2009). 
[19] Svante Hedström, Effective Core Potential (ECP) Basis Sets.

[20] M.J. Frisch, G.W. Trucks, H.B. Schlegel et al., Gaussian 03, Revision C.01 Gaussian Inc., Wallingford (CT) 2004.

[21] A.D. Becke, J. Chem. Phys. 98, 1372 (1993).

[22] A.D. Becke, J. Chem. Phys. 98, 5648 (1993).

[23] P.J. Stephens, F.J. Devlin, C.F. Chabalowski, M.J. Frisch, J. Phys. Chem. 98, 11263 (1994).

[24] C. Lee, W. Yang, R.G. Parr, Phys. Rev. 37, 785 (1988).
[25] K. Ragavachari, Q. Fu, G. Chen, L. Li, C.H. Li, D.C. Law, R.F. Hicks, J. Am. Chem. Soc. 124, 15119 (2002).

[26] R.F. Bennett, J.P. Connelly, J. Phys. Chem. 100, 9308 (1996).

[27] M.A. Todd, T.A. Baum, G. Bhandari, Stable Hydride Source Compositions for Manufacture of Semiconductor Devices and Structure, Patent No. WO1999027561A2, 1999.

[28] Xiaocheng Zhou, Yang Hang, Liren Liu, Zhuhua Zhang, Wanlin Guo, J. Am. Chem. Soc. 141, 7899 (2019). 